\title{
Q fever in Quebec (1989-93): Report of 14 cases
}

\author{
MONIQUe GOYeTte MD, ANDrÉ PoIRIER MD, JeAN BOUChARD MD, ERIC MORRIER BSC
}

\begin{abstract}
M Goyette, A Poirier, J Bouchard, E Morrier. $\mathrm{Q}$ fever in Quebec (1989-93): Report of 14 cases. Can $\checkmark$ Infect Dis 1994;5(3):113-118. Q fever, a zoonosis acquired by inhalation of the rickettsia Coxiella burnetii, is rarely diagnosed in Canada. The world incidence has been increasing since 1960, because of progressive dissemination of this microorganism in animal populations, particularly domestic ruminants. Some recent outbreaks were caused by cats. Of 14 cases reported in Quebec between 1989 and the beginning of 1993, nine occurred successively in an 18-month period in the rural region surrounding Trois-Rivières, after contact with livestock or cats. These cases are reported here, with the results of serological screening of the workers of an abattoir where one of the cases worked. Five additional cases reported in Quebec during the same period are briefly reviewed.
\end{abstract}

Key Words: Abattoir, Cat, Coxiella burnetii, $Q$ fever

\section{La fièvre $Q$ au Québec (1989-93) : Revue de 14 cas}

RÉSUMÉ : La fièvre Q, zoonose acquise par inhalation de la rickettsie Coxiella burnetii, demeure peu diagnostiquée encore au Canada. L'incidence mondiale est en hausse à cause de la dissémination progressive du microorganisme dans la population animale depuis 1960, en particulier au niveau des ruminants domestiques. Les chats ont été impliqués dans des éclosions récentes. Des 14 cas de fièvre $Q$ déclarés au Québec entre 1989 et début 1993, neuf se sont produits successivement en 18 mois dans la région rurale entourant Trois-Rivières, après contact avec des chats ou du bétail. Ils sont rapportés ici, avec les résultats du dépistage sérologique fait à l'abattoir où travaillait l'un des cas. Les cinq autres cas déclarés au Québec durant la même période sont brièvement décrits.

Q FEVER, A ZOONOSIS CAUSED BY THE RICKETTSIA COXIELLA burnetii, was recognized for the first time in 1935 during an outbreak in an Australian abattoir. Following this discovery, cases were recorded around the world in relation to animal breeding or the handling of their natural by-products (meat, wool, milk, fur, etc). The largest sources are found in cows, sheep and goats, which are generally asymptomatic, with the exception of abortions or stillbirths. Coxiella burnetii is a particularly virulent rickettsia as the inhalation of a very small quantity of the microorganism can cause the illness $(1,2)$. It is also quite resistant to harsh physicochemical conditions due to its ability to form spores: aerosols emitted during the birth of an animal, micturition, defecation or milking, for example, can last many weeks in the environment. The diagnosis is made serologically. The surface antigens of the microorganism vary during the infection; the antibodies of phase II are most dominant during the acute infection but are replaced by phase I antibodies during reactivation (chronic phase). 
The first Canadian cases were described in the Eastern Townships (Quebec) at the end of the 1950s. All cases were reported after contact with livestock (3-5). In the past decade, cats in Nova Scotia and Maine have been the cause of several outbreaks (6-8). The incidence of $\mathrm{Q}$ fever in Canada is not known as reporting is not required at the national level. Nine cases were described between 1960 and 1980 (9), followed by 328 cases from 1980 to 1987 (10); this rapid increase during the past decade very likely reflects the progressive spreading of this rickettsia among Canadian herds and domestic animals (5,9). A similar process occurred around the world during the same time period (11-13).

The clinical diagnosis of $\mathrm{Q}$ fever is difficult due to the lack of knowledge of local animal epidemiology and the variability of the clinical picture $(10,14)$ : the disease can be subclinical or manifest as a 'flu-like syndrome, granulomatous hepatitis, fever of unknown origin, atypical pneumonia, meningoencephalitis, or indolent endocarditis which becomes evident several years after the acute infection (15).

The Trois-Rivières region, located $140 \mathrm{~km}$ north-east of Montreal, has 450,000 residents, some of whom make their living from animal breeding and farming. Nine cases of $\mathrm{Q}$ fever in 18 months identified a previously unrecognized endemic focus in this region. The nine cases are described here, along with the results of a serological inquiry carried out among the workers of the abattoir where one of the patients worked. An additional five cases in the province of Quebec since 1989 are briefly described.

\section{PATIENTS AND METHODS}

Between May 1991 and January 1993, Q fever was serologically diagnosed in nine patients referred to the Service of Infectious Diseases at the Centre Hospitalier St-Joseph de Trois-Rivières for fever of undetermined origin. The complement fixation test was carried out using $C$ burnetii phase II antigen (Behring Institute, Germany); the diagnosis was based on the fourfold increase of titre (eight cases) or by the presence of a stable titre of at least 128 (one case) (16).

A serological inquiry was also performed at the abattoir where case I worked, plus a questionnaire on demographic data, animal contacts, diet and febrile illness antecedents.

Information on the five other cases was obtained through the Public Health Departments where cases were reported $(\mathrm{Q}$ fever must be reported by law to these departments since 1989 in Quebec).

\section{RESULTS}

The nine patients were all male with an average age of 48 years (range 33 to 66). Five cases were situated around Louiseville, a small city of 7000 residents, and the others in small rural villages around Trois-Rivières. The majority of the cases (seven of nine) occurred
TABLE 1

Epidemiological data and serologic results for the nine cases

\begin{tabular}{llc}
\hline $\begin{array}{l}\text { Occupation } \\
\text { (date) }\end{array}$ & Animals & $\begin{array}{c}\text { Serology (day } \\
\text { of evolution) }\end{array}$ \\
\hline $\begin{array}{l}\text { A) Physician } \\
\text { (May 1991) }\end{array}$ & Handling of a kitten & $0(4)$ \\
& & $2560(33)$ \\
B) Retired & Rural village. Lives 3 km & $160(15)$ \\
(June 1991) & from the abattoir of case I & $1280(29)$ \\
C) Farmer & Cattle, sheep, cats, dogs, & $0(5)$ \\
(July 1991) & rabbits & $320(18)$ \\
D) Professor & Brief contact with a cat & $0(4)$ \\
(August 1991) & & $256(13)$ \\
E) Labourer & Abandoned kittens in the & $0(9)$ \\
(October & neighbourhood & $256(23)$ \\
1991) & & $0(9)$ \\
F) Painter & Dog, cats, muskrats & $128(24)$ \\
(February & & $512(45)$ \\
1992) & & $0(7)$ \\
G) Mason & Acquisition of a new cat. \\
(May 1992) & Dogs, chickens, ducks, & $32(20)$ \\
& horses. Lives on a farm & $0(7)$ \\
H) School & Horses, ponies, geese, & $160(25)$ \\
monitor & 15-day-old kittens & $\geq 320(64)$ \\
(June 1992) & & \\
I) Abattoir & Sheep, cows, bison, deer, \\
butcher & one-year-old male cat & \\
(January & slightly seropositive & \\
1993) & & \\
\hline
\end{tabular}

between May and October. Patient $\mathrm{C}$ had a concomitant diagnosis of chronic lymphoid leukemia but his condition was good. All cases had a documented history of contact with cats, except for patient B who lived in close proximity to dairy farms and stables at $3 \mathrm{~km}$ from the abattoir where patient I worked, on the same rural route. For the eight other subjects (Table 1), cats were the only identified potential carriers for three, while the other five also had contact with farm animals. Three patients remembered that the contact involved kittens, younger than two months old and living in barns; no contact with parturient cats was documented.

The incubation period could be determined for only three patients and was between two and three weeks. For all patients, the illness began abruptly, with a medical consultation after an average delay of four days. All patients had a high fever (greater than $39^{\circ} \mathrm{C}$ ), lasting more than 10 days in the absence of adequate treatment. All complained of a rather severe persistent frontal headache, without other neurological symptoms. Seven patients were bedridden for several days because of considerable fatigue. Lack of appetite led to an average weight loss of $4.5 \mathrm{~kg}$. Six complained of prolonged chills, and four of temporary myalgias. Physical examinations showed patients were feverish and weak, but not toxic, without rash, meningism, cutaneous embolisms, hepatosplenomegaly, or abnor- 
mal pulmonary auscultation. During the first week of symptoms, the differential white blood cell count showed leukopenia at $5000 \times 10^{6} / \mathrm{L}$, and four of six with atypical lymphocytes. The white blood cell count normalized during the second week but in some patients it reached temporarily high counts at the beginning of the third week (up to 17,700). The diagnosis made at the first consultation was a viral infection. Patients $\mathrm{A}$ and $\mathrm{H}$, the worst affected, had anemia (hemoglobin 110 $\mathrm{g} / \mathrm{L})$. During the first week, patient A also suffered thrombocytopenia at $58 \times 10^{9}$ cells/L.

Five of the seven patients tested during the first two weeks showed cholestasis with light cytolysis, which resolved during the following month. The chest radiographs, blood cultures, and multiple serological analyses were negative except for the complement fixation serology for $\mathrm{Q}$ fever: the antibodies against phase II of $C$ burnetii appeared after about 10 days of illness (Table 1). Patient A, the most seriously affected, developed a transient anticomplementary serum, which delayed the diagnosis. After five weeks of evolution without treatment, this patient showed phase I antibody titre of 128 (also done by complement fixation test, at the Laboratory Centre for Disease Control in Ottawa); this is the limit for the diagnosis of chronic infection $(15,16)$ since the antibodies of this type are barely detectable in acute infection (17). Five patients underwent an echocardiography, which showed an aortic valvular sclerosis without vegetations in the two most severe cases $(\mathrm{A}, \mathrm{H})$. A bone marrow biopsy showed 'doughnut epithelioid granulomas' in these same two patients, indicating the presence of $Q$ fever (10) (Figure 1).

\section{INQUIRY IN AN ABATOIR}

Patient I, suffering from Q fever in January 1993, had been working in an abattoir just south of TroisRivières since the summer of 1992. The abattoir employed 16 people who had worked there for an average of seven years, with the exception of two individuals hired the week before the inquiry. Production consists mostly of cows and sheep coming from Quebec and Ontario; deer and bison are also sometimes handled. The slaughtering takes place in a large $100 \mathrm{~m}^{2}$ room.

Four months after the index case, a serological study and questionnaire were done for 14 of the 15 other workers (one being absent); two had antibodies against phase II $C$ burnetii in complement fixation (titre of 40 and 10). The first subject was a 29-year-old female inspector, raised on a farm, who had been working at the abattoir for five years. The other was a 38-year-old labourer who had been employed there for 18 months and who was an occasional raw meat eater. The responses of these two individuals concerning bouts of fever during the last two years was negative. If we add the index case, this gives a seroprevalence of 20\% (three of 15) for $\mathrm{Q}$ fever at this abattoir, comparable with Nova Scotia's abattoir workers in 1984 (18).

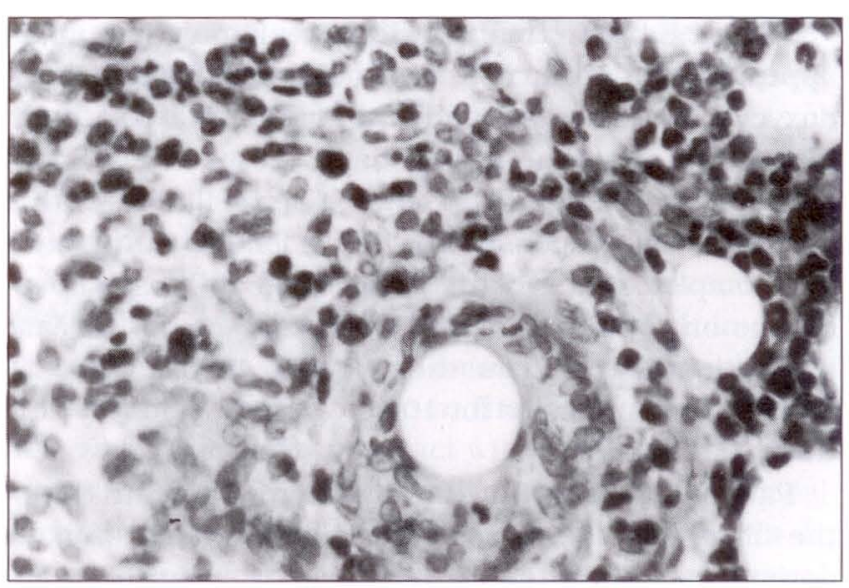

Figure 1) Bone marrow biopsy of patient A; doughnut granuloma is visible. Magnification $\times 180$. (Photograph courtesy of Dr Robert Perron, pathologist at St-Joseph Hospital)

\section{OTHER CASES IN QUEBEC SINCE 1989}

Five other cases were reported on the basis of serological diagnosis in Quebec between 1989 and 1993. The first three occurred in the Eastern Townships. In June 1990, a 41-year-old butcher presented with fever, headache and severe fatigue accompanied by abnormal hepatic tests. At the beginning of 1992, a 78-year-old man suffering from cancer died of pneumonia caused by $\mathrm{Q}$ fever; he had lived on a farm. A 63-year-old dairy cow breeder had a fever of unknown origin in June 1992; he also was in contact with cats, dogs and rabbits and he consumed unpasteurized milk.

The last two cases were in the region of Rimouski, in eastern Quebec. In September 1992, a 53-year-old sheep breeder had a febrile syndrome for two weeks after he assisted a ewe giving birth to a stillborn lamb. The provincial animal pathology laboratory (personal communication) performed a serological screening of 10 randomly chosen adult sheep among the 150 animals in the herd. Eight of 10 showed positive serology for $\mathrm{Q}$ fever in complement fixation, while results were negative for the cat and dog of the same farm. In April 1993, a 33-year-old clothing store owner was hospitalized for persistent fever; the only animal contact was a 5 min visit to a sheep pen 14 days before. The laboratory tests showed, one week after the beginning of symptoms, leukopenia $\left(2300 \times 10^{6}\right.$ cells $\left./ L\right)$, thrombocytopenia $\left(89 \times 10^{9}\right.$ cells $\left./ \mathrm{L}\right)$, mild hepatic abnormalities and $\mathrm{Q}$ fever seroconversion.

\section{EVOLUTION AND TREATMENT}

As in all diseases where diagnosis is made serologically, treatment was delayed for several patients. $\mathrm{Pa}-$ tients $\mathrm{B}$ and $\mathrm{D}$ received no antibiotic treatment during the acute illness; the relatively severe acute phase lasted two weeks, and two more weeks passed before the patients achieved spontaneous clinical recovery sufficient (90\%) to permit return to work. Doxycycline was administered afterward. 
Patient E began treatment one week after symptoms appeared, and returned to work after three days of doxycycline. Patients $\mathrm{C}$ and $\mathrm{F}$ received a brief treatment (three and one-and-a-half days, respectively) with tetracyclines during the first week of the illness, with a rapid clinical response. The treatment by antibiotics was completed later. Patient I received $100 \mathrm{mg}$ of doxycycline once daily from day 18 to day 28 , for disease prevention for travellers; the clinical response was slow and the fever persisted for 10 days after the doxycycline treatment ended.

Patient $\mathrm{G}$ received erythromycin from the fifth day of the illness, a medication considered to be less than optimal for $\mathrm{Q}$ fever (19-21). Although the clinical evolution was satisfactory, classic treatment was subsequently administered.

Patient A, with aortic valvular sclerosis, had a severe clinical syndrome requiring hospitalization. Several antibiotics were administered successively during five days (cefuroxime, ciprofloxacin, imipenen, and erythromycin), with some clinical improvement. After the treatment, clinical deterioration with weight loss of $9 \mathrm{~kg}$ and a high fever for four weeks occurred. Treatment with ciprofloxacin was finally initiated $(500 \mathrm{mg}$ twice daily for 15 weeks), with rifampin (300 mg twice daily for the first three weeks). Clinical recovery, which began during the first week of treatment, was estimated to be $80 \%$ after four weeks and $100 \%$ at 15 weeks. At that time, treatment was stopped and a notable drop in phase II antibodies was observed (titre of 5120 at the beginning and 640 at the end of treatment). The patient's condition remains good after almost three years of follow-up.

Patient $\mathrm{H}$, also with aortic valvular sclerosis, was treated with doxycycline from day 7 to 18 of illness, with a transitory response of fever and headache; clinical relapse occurred during treatment. From day 25 he was treated with ciprofloxacin (750 mg twice daily) and rifampin (300 mg twice daily), with a satisfactory clinical recovery one week later. This treatment was continued for seven weeks until complete recovery was reached.

\section{DISCUSSION}

Our cases suggest that $\mathrm{Q}$ fever should be considered when a middle-aged man, previously in good health, consults for high and prolonged fever, accompanied by a severe frontal headache, without an obvious infectious site. The presence of a mild hepatic abnormality (transaminases two to three times normal level), should raise suspicion. Although the white blood cell count is described as normal in the literature (21), or slightly increased (10), the observations made here suggest that leukopenia with the presence of atypical lymphocytes develops temporarily during the first week of symptoms.

Severe headache is a predominant symptom at presentation, and may be accompanied by neurological signs of meningoencephalitis (22-25). Pulmonary manifestations previously reported include incidental radiological findings of multiple small, rounded, segmental infiltrations, slowly resolving $(7,8,10,26)$. Severe pneumonia is sometimes described $(22,27,28)$.

$\mathrm{C}$ burnetii strains are of variable virulence and cause different clinical manifestations, depending on the country $(10,16,27)$. Endocarditis is principally described in England and in Australia. In rural Nova Scotia, $Q$ fever is a frequent cause of pneumonia $(29,30)$. In Ontario (31), the clinical manifestations seem to be comparable to those of our region with fever of unknown origin affecting middle-aged men; hepatic abnormalities, bone marrow or hepatic granulomas, and anticomplementary serum were found frequently.

The severity of the acute infection increases with age $(8,14,22,27)$; infected children show little or no symptoms (14). Exposure to a high density of aerosols reduces the incubation period and increases the clinical severity $(6,32)$. Transmission among humans does not occur.

Acute infection can heal spontaneously but reactivation may occur, rarely, several years later in subjects with valvular disease (15). It presents principally as an indolent endocarditis resistant to treatment $(15,33,34)$. Also, certain immunocompromised patients without valvular disease developed endocarditis (35). Chronic infection sometimes develops in the form of vascular infection, osteomyelitis or chronic hepatitis (34). In an endemic area, a persistent fever in an immunocompromised patient, or the appearance of sudden unexplained valvular damage (46), must lead to the exclusion of chronic $Q$ fever.

Another obstacle to diagnosis is the lack of recent data on the endemicity of $Q$ fever in animals in Quebec. In rural areas, exposure to animal aerosols is frequent, especially in spring and summer. Occupational history is important, as well as animal contacts in the month preceding the onset of the disease. The incubation is usually between 14 and 20 days (ranging from four to 39).

The diagnosis of $Q$ fever is generally made by seroconversion in complement fixation against the phase II antigens of $C$ burnetii; this method suffers the usual diagnostic delay, a lack of sensitivity, and interference due to the appearance of anticomplementary sera in some patients suffering from $\mathrm{Q}$ fever (31). More sensitive methods exist, such as indirect immunofluorescence and ELISA. IgM screening is not currently available and is subject to interference by rheumatoid factor, which can appear during $Q$ fever. If only one convalescent serum is available, phase II IgG titre is at least 128 by complement fixation is suggestive of acute Q fever (16).

The culture of $C$ burnetii may be done in cell culture $(19,23,35)$ but is hazardous; inhalation of a single rickettsia is enough to cause illness $(1,2)$. Diagnosis is 
assisted by hepatic or bone marrow biopsies showing the characteristic 'doughnut granulomas', surrounded by a dense ring of fibrin, with a central lipidic vacuole. These granulomas were identified in the bone marrow of cases $\mathrm{H}$ and $\mathrm{A}$ (Figure 1).

Diagnosis of chronic infection is made by showing the presence of antibodies against phase I of the microorganism at a titre of 200 or greater in complement fixation. We think that patient A, an aortic sclerosis carrier whose phase I count reached 128, must be followed in the future because of the risk of reactivation. Where available, the appearance of phase I IgA is generally considered diagnostic of an endocarditis in the literature (36).

The treatment of acute infections consists of two weeks of doxycycline. This generally brings down the fever in two to three days $(32,37,38)$. Studies in cell cultures $(19,39)$ reveal that $C$ burnetii strains isolated in the acute phase are clearly more sensitive to antibiotics than the strains isolated during the reactivations; several authors suggest that an early diagnosis, associated with an adequate treatment administered as soon as possible, could be important in the prevention of reactivations $(14,39,40)$. That is why all our patients were treated, though sometimes late. We obtained excellent clinical results with the combination of ciprofloxacin and rifampin in patient A (prolonged acute infection) and in patient $\mathrm{H}$ (clinical relapse under doxycycline). This combination was synergistic and very effective in vitro (39). The quinolones are also being tried for chronic infections (41-43). The authors generally suggest that the treatment of the chronic infection include two antibiotics during a minimum of two to three years $(10,34,42)$. In spite of this, more than half

ACKNOWLEDGEMENTS: The authors thank colleagues from Public Heath Departments (Rimouski, Sherbrooke and TroisRivières), Laboratoire Provincial de Pathologie Animale du Québec, and Dr Robert Perron (Trois-Rivières) for providing data for study. The authors also thank the staff of St-Gregoire's abattoir for their collaboration, and $\mathrm{Mr}$ Richard Leblanc for manuscript editing.

\section{REFERENCES}

1. Tigertt WD, Benenson AS, Gochenour WS. Airborne Q fever. Bacteriol Rev 1961;25:285-93.

2. Ormsbee R, Peacock M, Gerloff R, Tallent G, Wike D. Limits of rickettsial infectivity. Infect Immunol 1978; 19:239-45.

3. Pavilanis V, Duval L, Foley AR, LHeureux M. An epidemic of $\mathrm{Q}$ fever at Princeville, Québec. Can J Public Health 1958;49:520-9.

4. Marc-Aurèle J, Grégoire F, Comeau M. Clinical report on Q fever - First case in Canada. Can Med Assoc J 1956;75:931-3.

5. McKiel JA. $\mathrm{Q}$ fever in Canada. Can Med Assoc J 1964:91:573-7.

6. Marrie TJ, Durant H, Williams JC, Mintz E, Waag DM. Exposure to parturient cats: A risk factor for acquisition of these patients required a valvular replacement because of hemodynamic instability, on average 107 days after beginning treatment.

\section{CONCLUSION}

Which animals transmit $\mathrm{Q}$ fever in the Trois-Rivières region? Cats are particularly suspect here, since contact with them has been well documented to have occurred in eight of the nine patients; in the rural area, several abandoned cats live in the various farm buildings, where they are in contact with livestock and small rodents. With the exception of case I, no serological screening was done in family members, colleagues or animals because they were asymptomatic. A serological study is being conducted to determine the degree of contamination of the herds and domestic animals.

In the endemic areas, as our region is likely to be, the serology for $\mathrm{Q}$ fever should be considered in the presence of fever or hepatitis of unknown origin, pneumonia accompanied with headache or culture-negative endocarditis. It is likely that most cases are missed because physicians are not aware enough of $\mathrm{Q}$ fever. The disease in our region does not seem to give the predominant pulmonary manifestations observed in Nova Scotia $(29,30)$; we are now performing a serological study to determine the importance of $\mathrm{Q}$ fever in community acquired pneumonia. The observation of lymphopenia, in the first week of symptoms sometimes with atypical lymphocytes, is particularly interesting.

In the future, prevention in rural areas will be done by teaching animal handlers the basic hygienic precautions such as destroying of animal placentas and the disinfection of birthing areas. A vaccine should also be available in the coming years $(44,45)$.

of $\mathrm{Q}$ fever in Maritime Canada. J Infect Dis 1988; 158:101-8.

7. Langley JM, Marrie TJ, Covert A, Waag DM, Williams JC. Poker players' pneumonia. N Engl J Med 1988;319:354-6.

8. Pinsky RL, Fishbein DB, Greene CR, Gensheimer KF. An outbreak of cat-associated $Q$ fever in the United States. $J$ Infect Dis 1991;164:202-4.

9. Lang GH. $Q$ fever: An emerging public health concern in Canada. Can J Vet Res 1989;53:1-6.

10. Marrie TJ. Q fever - A review. Can Vet J 1990;31:555-63.

11. Akesson A, Macellaro A, Tull P, Williams JC, Norlander L. Epidemiology of $Q$ fever in Sweden. Scand J Infect Dis 1991;23:153-7.

12. Connolly JH, Coyle PV, Adgey AA, O'Neill HJ, Simpson DM. Clinical 3 fever in Northern Ireland 1962-1989. Ulster Med J 1990;59:137-44.

13. Yoshiie K, Oda H, Nagano N, Matayoshi S. Serological evidence that the $\mathrm{Q}$ fever agent (Coxiella burnetii) has spread widely among dairy cattle of Japan. Microbiol Immunol 1991;35:577-81.

14. Dupuis G, Péter O, Pedroni D, Petite J. Aspects cliniques observés lors d'une epidémie de 415 cas de fièvre $Q$. Schweiz Med Wochenschr 1985;115:814-8.

15. Wilson HG, Neilson GH, Galea EG, Stafford G, O'Brien MF. $Q$ fever endocarditis in Queensland. Circulation 1976;53:680-4. 
16. Simor AE. Q fever - Human disease in Ontario. Can Vet $\mathrm{J}$ 1987;28:264-6.

17. Winner SJ, Eglin RP, Moore VIM, Mayon-White RT. An outbreak of $\mathrm{Q}$ fever affecting postal workers in Oxfordshire. J Infect 1987; 14:255-61.

18. Marrie TJ, Fraser J. Prevalence of antibodies to Coxiella burnetii among veterinarians and slaughterhouse workers in Nova Scotia. Can Vet J 1985;26:181-4.

19. Yeaman MR, Mitscher LA, Baca OG. In vitro susceptibility of Coxiella burnetii to antibiotics, including several quinolones. Antimicrob Agents Chemother 1987;31:1079-84

20. Sobradillo V, Zalacain R, Capelastegui A, Uresandi F, Corral J. Antibiotic treatment of pneumonia due to $Q$ fever. Thorax 1992;47:276-8.

21. Sobradillo V, Ansola P, Baranda F, Corral C. Q fever pneumonia: A review of 164 community-acquired cases in the Basque country. Eur Respir J 1989;2:263-6.

22. Marrie TJ. Coxiella burnetii (Q fever). In: Mandell GL, Douglas RG, Bennett JE, eds. Principles and Practice of Infectious Diseases, 3rd edn. New York: Churchill Livinstone, 1990:1472-6.

23. Drancourt M, Raoult D, Xeridat B, Milandre L, Nesri M, Dano P. Q fever meningoencephalitis in five patients. Eur J Epidemiol 1991;7:134-8.

24. Kohler J, Mergner T, Bohle M, Neumann-Haefelin D. Neurologic complications of $\mathrm{Q}$ fever. Fortschr Neurol Psychiatr 1992;60:110-3.

25. Ferrante MA, Dolan MJ. Q fever meningoencephalitis in a soldier returning from the Persian Gulf war. Clin Infect Dis 1993; 16:489-96.

26. Smith DL, Wellings R, Walker C, Ayres JG, Burge PS. The chest $x$ ray in $Q$ fever: A report on 69 cases from the 1989 West Midlands outbreak. Br J Radiol 1991;64:1101-8.

27. Dupont HT, Raoult D, Brouqui P, et al. Epidemiologic features and clinical presentation of acute $\mathrm{Q}$ fever in hospitalized patients: 323 French cases. Am J Med 1992;93:427-34.

28. Marrie TJ. Q fever pneumonia. Semin Respir Infect 1989:4:47-55.

29. Marrie TJ, Haldane EV, Faulkner RS, Kwan C, Grant B, Cook F. The Importance of Coxiella burnetii as a cause of pneumonia in Nova Scotia. Can J Public Health 1985;76:233-6.

30. Marrie TJ, Durant H, Yates L. Community-acquired pneumonia requiring hospitalisation: 5-year prospective study. Rev Infect Dis 1989;11:586-99.
31. Vellend H, Salit IE, Spence L, et al. Q fever - Ontario. Can Dis Wkly Rep 1982;8:171-2.

32. $\mathrm{Q}$ fever outbreak - Switzerland. MMWR 1984;33:355-61.

33. Marrie TJ. A comparison of $\mathrm{Q}$ fever endocarditis with native valve endocarditis. Ann NY Acad Sci 1990;590:61-7.

34. Raoult D, Levy PY, Harlé JR, et al. Chronic Q fever: Diagnosis and follow-up. Ann NY Acad Sci 1990;590:51-60.

35. Raoult D, Brouqui P, Marchou B, Gastaut JA. Acute and chronic $Q$ fever in patients with cancer. Clin Infect Dis 1992; 14:127-30.

36. Peacock MG, Philip RN, Williams JC, Faulkner RS. Serological evaluation of $\mathrm{Q}$ fever in humans: Enhanced phase 1 titers of immunoglobulins $\mathrm{G}$ and $\mathrm{A}$ are diagnostic for $\mathrm{Q}$ fever endocarditis. Infect Immun 1983;41:1089-98.

37. $\mathrm{Q}$ fever among slaughterhouse workers - California. MMWR 1986;35:223-6.

38. Bertrand A, Janbon F, Jonquet O, Reynes J. Rickettsiaceae infections and fluoroquinolones. Pathol Biol 1988;36:493-5.

39. Yeaman MR, Roman MJ, Baca OG. Antibiotic susceptibilities of two Coxiella burnetii isolates implicated in distinct clinical syndromes. Antimicrob Agents Chemother 1989;33:1052-7.

40. Sawyer LA, Fishbein DB, McDade JE. Q fever: Current concepts. Rev Infect Dis 1987;9:935-45.

41. Yebra M, Ortigosa J, Albarran F, Crespo MG. Ciprofloxacin in a case of $\mathrm{Q}$ fever endocarditis. $\mathrm{N}$ Engl $\mathrm{J}$ Med 1990;323:614.

42. Levy PY, Drancourt M, Etienne J, et al. Comparison of different antibiotic regimens for therapy of 32 cases of $Q$ fever endocarditis. Antimicrob Agents Chemother 1991:35:533-7.

43. Cacoub P, Wechsler B, Chapelon C, Thibon M, Godeau P. Q f fever endocarditis and treatment with the fluoroquinolones. Arch Intern Med 1991;151:816-8.

44. Marmion BP, Ormsbee RA, Kyrkou M, et al. Vaccine prophylaxis of abattoir-associated $Q$ fever: Eight years' experience in Australian abattoirs. Epidemiol Infect 1990; 104:275-87.

45. Shapiro RA, Siskind V, Schofield FD, Stallman N, Worswick DA, Marmion BP. A randomized, controlled, double-blind, cross-over, clinical trial of $\mathrm{Q}$ fever vaccine in selected Queensland abattoirs. Epidemiol Infect 1990; 104:267-73.

46. Etienne J, Delahaye F, Raoult D, Frieh JP, Loire R, Delaye J. Acute heart failure due to $\mathrm{Q}$ fever endocarditis. Eur Heart J 1988;9:923-6. 


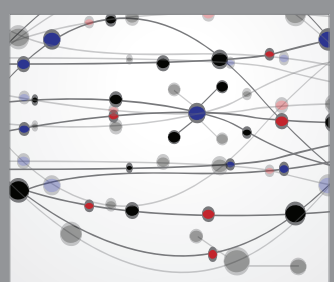

The Scientific World Journal
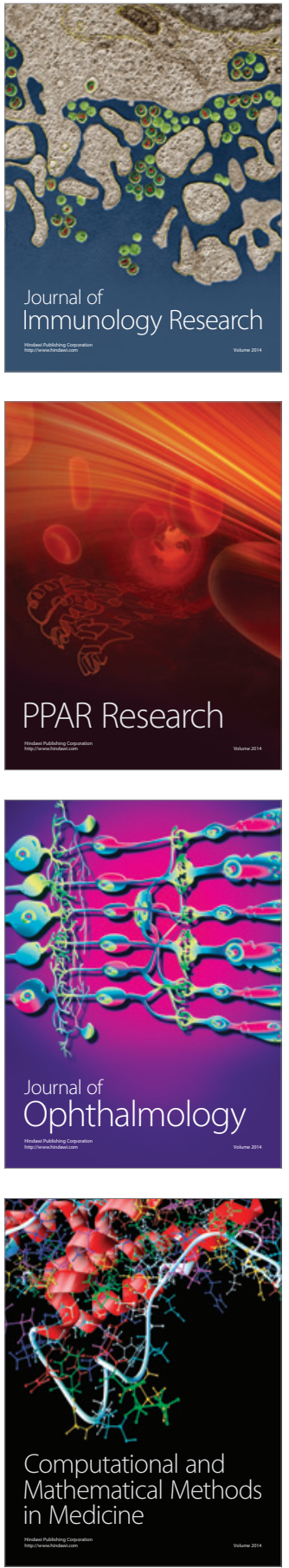

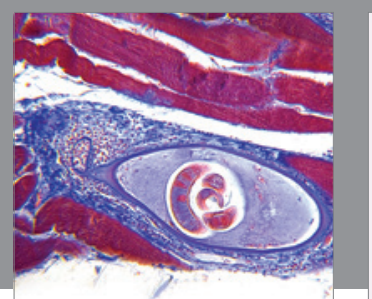

Gastroenterology Research and Practice

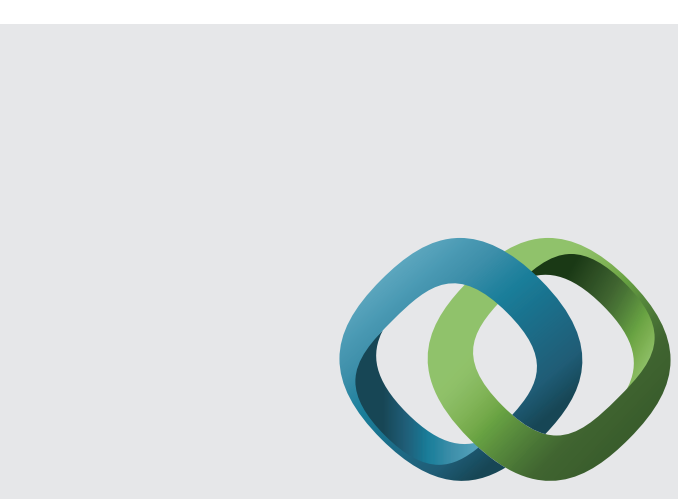

\section{Hindawi}

Submit your manuscripts at

http://www.hindawi.com
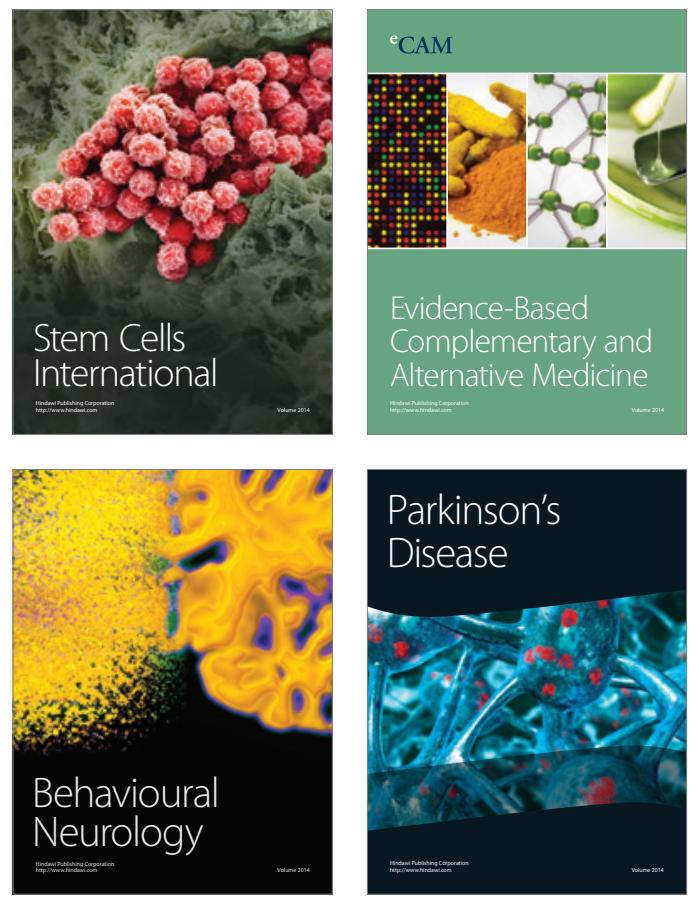
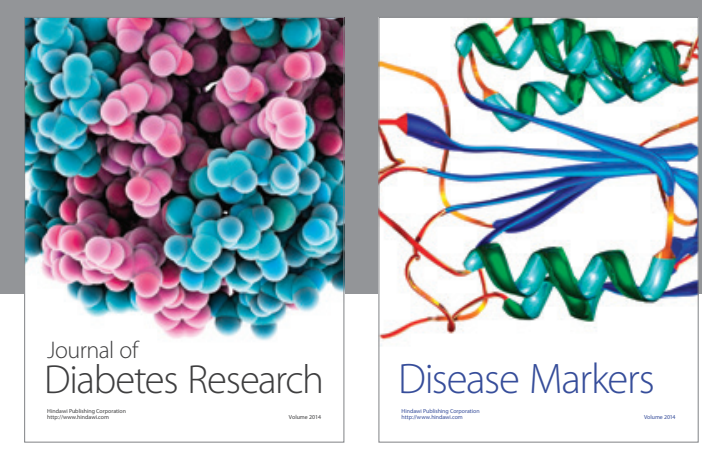

Disease Markers
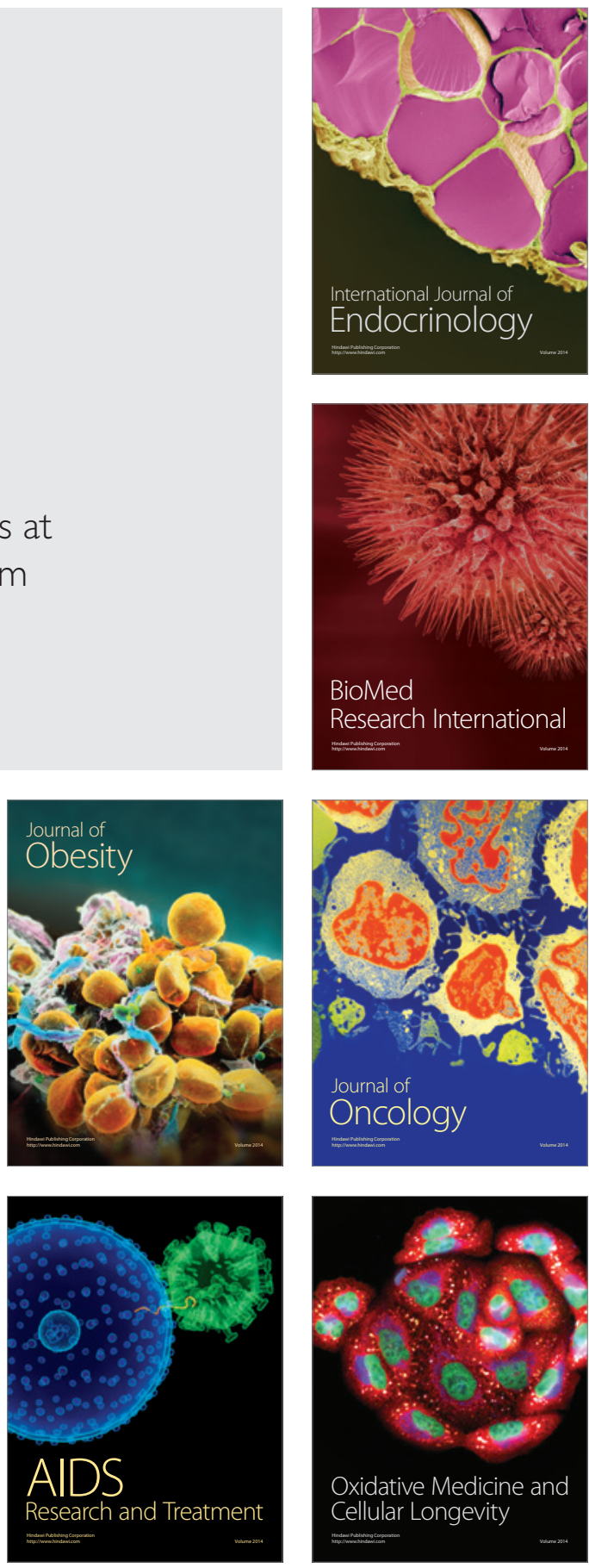